\title{
The Influence of Single Nucleotide Polymorphisms and Adjuvant Radiotherapy on Systemic Inflammatory Proteins, Chemokines and Cytokines of Patients With Breast Cancer
}

\author{
NONGNIT LAYTRAGOON LEWIN ${ }^{1,2}$, THITIYA LUETRAGOON ${ }^{1,3}$, \\ BENGT-ÅKE ANDERSSON ${ }^{1,2}$, DELMY OLIVA ${ }^{2,4}$, MATS NILSSON ${ }^{5}$, MICHAEL STRANDEUS $^{4}$, \\ STURE LÖFGREN ${ }^{1}$, LARS-ERIK RUTQVIST ${ }^{6}$ and FREDDI LEWIN ${ }^{4}$ \\ ${ }^{1}$ Department of Laboratory Medicine, Ryhov Hospital, Jönköping, Sweden; \\ ${ }^{2}$ Department of Clinical and Experimental Medicine, Linköping University, Linköping, Sweden; \\ ${ }^{3}$ Department of Medical Technology, Naresuan University, Phitsanulok, Thailand; \\ ${ }^{4}$ Department of Oncology, Ryhov Hospital, Jönköping, Sweden; \\ ${ }^{5}$ Futurum, Ryhov Hospital, Jönköping, Sweden; \\ ${ }^{6}$ Scientific Affairs Group, Swedish Match AB, Stockholm, Sweden
}

\begin{abstract}
Independently of tumour and treatment modulation, the host immune response status plays an important role in the clinical outcome of patients with cancer. The influence of single nucleotide polymorphisms (SNPs) and adjuvant radiotherapy (RT) on the systemic immune response status of patients with breast cancer was investigated. Materials and Methods: Eighty-six female patients recovering from breast cancer surgery were investigated. As a control cohort, 82 healthy female blood donors were used. Blood-based SNPs, plasma C-reactive protein (CRP), cytokines and chemokines were analyzed for this purpose. Results: Independently of tumour stage and hormone receptor status, dysregulation of plasma CRP, chemokine (C-C motif) ligand 4 (CCL4) and interleukin 2 (IL2), but not CCL5, CCL2, platelet-derived growth factor, IL6, IL10, IL12, interferon-gamma or tumour necrosis factor alpha were detected in the patients when compared to controls. The extent of alteration in plasma levels of CRP and IL2 patients was significantly associated with SNPs in CRP rs 1800947 and IL2 rs6822844, respectively. These SNPs had no influence on the levels of corresponding plasma biomarkers in the healthy controls. Adjuvant RT reduced plasma CRP and CCL5 levels in patients with regards to CRP rs1800947CC, CCL5 rs2107538GG and CCL5 rs2280789AA sequences. Conclusion: Dysregulation of
\end{abstract}

Correspondence to: Nongnit Laytragoon Lewin, Ph.D., Laboratory Medicine, Ryhov Hospital, SE-551 85 Jönköping, Sweden. E-mail: nongnit.lewin@rjl.se

Key Words: Adjuvant radiotherapy, breast cancer, blood-based biomarkers. immune responses, as indicated by plasma levels of CRP, CCL4 and IL2 were found in patients with breast cancer despite the removal of the tumour mass. The benefit of adjuvant RT, as indicated by reduced plasma amounts of inflammatory protein CRP and chemokine CCL5 were based on the SNPs of the patients. Analyses of blood-based SNPs, plasma CRP, IL2 and CCL5 are low cost, rapid and can be carried out using general laboratory facilities while requiring only a peripheral blood sample. The possibility of using these blood-based biomarkers as an indicator of patient immune status for selection of individual patient treatment warrants further investigation.

Adjuvant radiotherapy (RT) is an essential treatment of breast cancer and various types of solid tumours after surgery. Independently of tumour and treatment modulation, the host immune response status plays an important role in the clinical outcome of patients with cancer (1). Recently, a combination of RT and immunotherapy was suggested (2-4).

The anti-neoplastic properties of RT are primarily related to induction of DNA damage and cell death. Bystander effects can also develop in cells not directly hit by RT (5).These processes can in turn lead to the alteration of host immune responses driven by intra- and intercellular communication via inflammatory proteins, chemokines and cytokines (6-9).

The intensity of host systemic inflammatory responses can be assessed by monitoring the level of plasma C-reactive protein $(\mathrm{CRP})(10,11)$. Following the recovery stage, the plasma CRP level returns to a normal value. Increased plasma CRP levels were associated with a poor clinical outcome in patients with cancer independently of tumournode-metastasis (TNM) staging (12). 
Cytokines are small proteins that regulate local intercellular and systemic immune responses. One of these, interleukin 2 (IL2), is a potent immunomodulatory cytokine and has been used as single therapy for cancer (13). Chemokines are chemotactic cytokines that mediate host inflammatory responses, leukocyte trafficking and T-cell or natural killer (NK) cell activities (14-16). Chemokine (C-C motif) ligand (CCL4) and CCL5 are highly expressed in breast tumour cells and various cells in the tumour microenvironment but are minimally expressed in normal breast epithelial cells (17). The administration of anti-inflammatory chemokines was found to protect multipotent hematopoietic cells from the cytotoxic effects of chemotherapy (16). The use of anti-inflammatory chemokines as immunotherapy in patients with cancer has been suggested $(16,18-20)$.

The levels of inflammatory proteins, chemokines and cytokines are suggested to be associated with individual genetic variations $(6,8,9)$. Major contributors to genetic variations are single nucleotide polymorphisms (SNPs) found within DNA sequences $(9,21)$.

The present study aimed to determine systemic immune responses of patients after recovery from surgery for breast cancer, as well as the influence of adjuvant RT and SNPs. Low-cost and rapid blood-based biomarkers were selected for this purpose. CRP, chemokines and cytokines in association with SNPs in the corresponding genes were analysed.

\section{Materials and Methods}

Patients and controls. Eighty-six female patients with breast cancer aged over 18 years and scheduled for standard adjuvant RT after breast cancer surgery were invited to participate. If they accepted the invitation, peripheral blood was drawn twice. The first, baseline, sample was obtained after the patient recovered from cancer surgery and before the commencement of adjuvant RT (R0). The second, follow-up, blood sample was obtained directly after completion of adjuvant RT (R1).

Eighty-two female healthy blood donors with no history of cancer or using any immunomodulation agents were included as controls. One peripheral blood sample was obtained.

Informed consent was obtained from all participants. The study was conducted in accordance with the Declaration of Helsinki and the Ethical Board at Linköping University approved this investigation, Dnr 2010/331-31.

Adjuvant RT. Adjuvant RT was delivered at the Department of Oncology, Ryhov Hospital, Sweden using Varian True Beam machines (Varian, Palo Alto, CA, USA). The patients received standard treatment with a total of 50 Gy to the operated breast in 25 fractions, 1 fraction per day administered 5 times per week for a total of 5 weeks.

Plasma CRP analysis. The level of high-sensitive CRP in the plasma of the controls and patients at R0 and R1 were analysed using Siemens Adevia 1800 (Siemens Healthcare, Erlangen, Germany) with reagents and protocols from this company.
Table I. The characteristics of 86 female patients with breast cancer.

\begin{tabular}{lc}
\hline Tumour characteristic & $\mathrm{n}$ \\
\hline Stage & \\
T1 & 48 \\
$>\mathrm{T} 1$ & 24 \\
Tis & 14 \\
Lymph node status & \\
N0 & 68 \\
$>$ N0 & 18 \\
Histology & \\
DCIS & 11 \\
Ductal & 54 \\
Lobular & 14 \\
Tubular & 7 \\
Receptor expression & \\
ER+ & 13 \\
HER2+ & 5 \\
ER+HER2+ & 2 \\
ER+PR+ & 49 \\
ER+PR+HER2+ & 3 \\
Triple-negative & 3 \\
N/A & 11 \\
\hline
\end{tabular}

ER: Oestrogen receptor; HER2: human epidermal growth factor receptor; PR: progesterone receptor; N/A: not available.

Plasma cytokine and chemokine analysis. Based on previous investigations, plasma IL2, IL6, IL10, IL12, interferon-gamma (IFN $\gamma)$ or tumour necrosis factor alpha (TNF $\alpha)$, CCL2, CCL4, CCL5 and platelet-derived growth factor (PDGF)-bb were selected as candidate blood-based biomarkers $(1,12,21,22)$. Customised fluorochrome kits for multiplex fluorochrome technique (Luminex xMAPTM Technology, Austin, TX, USA) were purchased from BioRad Laboratories (Bio-Rad Laboratories, Hercules, CA, USA). The levels of plasma cytokines and chemokines were analysed according to the Bio-Rad Laboratories protocol (www.Bio-Rad.com/bioPlex/x-Plex).

DNA and SNP analysis. High-molecular weight DNA was extracted from peripheral blood samples using Qiagen Bio Robot M48 with MagAttract DNA Blood M48 kits (Qiagen, Hilden, Germany). For SNP analysis, all genotypes fulfilling the Hardy-Weinberg equilibrium (chi-squared test, $p<0.05$ ) were used. SNPs in genes associated with CRP, IL2, CCL4 and CCL5 expression that showed a tendency for association $(p<0.1)$ between levels in controls $v s$. patient at $\mathrm{R}_{0}$ or between patient levels at $\mathrm{R}_{0} v s . \mathrm{R}_{1}$ were investigated.

The selected SNPs were CRP rs1800947, IL2 rs6822844, CCL4 rs1719153, CCL5 rs2107538 and CCL5 rs2280789. All of these sequences were tested and passed two hits in the dbSNP database and were HapMap-validated with an Illumina design ability score according to the manufacturer's protocol (23). The genotyping of the SNPs was performed by Illumina Golden Gate Genotyping assay at the SNP \& SEQ Technology Platform, Uppsala University, Sweden (http://www.genotyping.se).

Statistics. Student's $t$-tests were used for comparing the plasma levels of proteins, chemokines and cytokines between the control 
Table II. Plasma level (Mean $\pm S D)$ of C-reactive protein (CRP), cytokines and chemokines in healthy blood donors (Controls) and patients with breast cancer before $\left(R_{0}\right)$ and after $\left(R_{1}\right)$ adjuvant radiotherapy.

\begin{tabular}{|c|c|c|c|c|c|}
\hline \multirow[b]{2}{*}{ Parameter } & \multirow[b]{2}{*}{ Controls } & \multicolumn{2}{|c|}{ Patients } & \multicolumn{2}{|c|}{$p$-Value } \\
\hline & & $\mathrm{R}_{0}$ & $\mathrm{R}_{1}$ & R0 vs. Controls* & $\mathrm{R}_{0}$ vs. $\mathrm{R}_{1} * *$ \\
\hline CRP (mg/l) & $2.4 \pm 0.3$ & $4.3 \pm 0.5$ & $4.3 \pm 0.4$ & 0.001 & 0.07 \\
\hline PDGF (pg/ml) & $677 \pm 61$ & $649 \pm 63$ & $569 \pm 62$ & 0.75 & 0.25 \\
\hline IL2 (pg/ml) & $24 \pm 2$ & $15 \pm 2$ & $14 \pm 2$ & 0.003 & 0.59 \\
\hline IL6 (pg/ml) & $25 \pm 2$ & $21 \pm 2$ & $18 \pm 2$ & 0.19 & 0.16 \\
\hline IL10 (pg/ml) & $28 \pm 9$ & $18 \pm 2$ & $15 \pm 2$ & 0.24 & 0.09 \\
\hline IL12 (pg/ml) & $53 \pm 20$ & $31 \pm 6$ & $25 \pm 3$ & 0.30 & 0.08 \\
\hline $\mathrm{IFN} \gamma(\mathrm{pg} / \mathrm{ml})$ & $139 \pm 10$ & $145 \pm 13$ & $126 \pm 12$ & 0.71 & 0.13 \\
\hline $\mathrm{TNF} \alpha(\mathrm{pg} / \mathrm{ml})$ & $70 \pm 5$ & $69 \pm 6$ & $66 \pm 6$ & 0.84 & 0.65 \\
\hline CCL2 (pg/ml) & $161 \pm 7$ & $141 \pm 8$ & $141 \pm 8$ & 0.06 & 0.97 \\
\hline CCL4 (pg/ml) & $46 \pm 2$ & $54 \pm 2$ & $50 \pm 3$ & 0.0042 & 0.12 \\
\hline CCL5 $(\mathrm{pg} / \mathrm{ml})$ & $5835 \pm 268$ & $5584 \pm 220$ & $4862 \pm 246$ & 0.47 & 0.01 \\
\hline
\end{tabular}

CCL: Chemokine (C-C motif) ligand; IL: interleukin; PDGF: platelet-derived growth factor; IFN $\gamma$ : interferon-gamma; TNF $\alpha$ : tumour necrosis factor alpha. *Student's $t$-test. **Paired Student's $t$-test.

Table III. Influence of single nucleotide polymorphisms (SNP) on plasma levels (Mean \pm SD) of C-reactive protein (CRP), interleukin 2 (IL2), chemokine (C-C motif) ligand 4 (CCL4) and CCL5 among controls.

\begin{tabular}{|c|c|c|c|c|c|c|}
\hline Parameter & SNP & Genotype & $\mathrm{n}$ & Plasma level & & $p$-Value \\
\hline \multirow[t]{2}{*}{ CRP (mg/l) } & CRP rs 1800947 & $\mathrm{CC}$ & 70 & $2.3 \pm 0.3$ & $\mathrm{CC} v s . \mathrm{CG}$ & 0.92 \\
\hline & & CG & 12 & $2.9 \pm 1.3$ & & \\
\hline \multirow{2}{*}{ IL2 (pg/ml) } & IL2 rs6822844 & $\mathrm{AC}$ & 34 & $26.7 \pm 4$ & AC vs. CC & 0.92 \\
\hline & & $\mathrm{CC}$ & 48 & $22.3 \pm 2.6$ & & \\
\hline \multirow[t]{2}{*}{ CCL4 (pg/ml) } & CCL4 rs1719153 & $\mathrm{AT}$ & 46 & $45.6 \pm 2.6$ & AT vs.TT & $>0.99$ \\
\hline & & TT & 35 & $45.6 \pm 3.6$ & & \\
\hline \multirow[t]{2}{*}{ CCL5 (pg/ml) } & CCL5 rs2107538 & AG & 22 & $5507 \pm 560$ & AG $v s . \mathrm{GG}$ & $>0.99$ \\
\hline & & GG & 60 & $5955 \pm 305$ & & \\
\hline \multirow[t]{2}{*}{ CCL5 (pg/ml) } & CCL5 rs2280789 & $\mathrm{AA}$ & 65 & $6044 \pm 291$ & AA vs. AG & 0.65 \\
\hline & & $\mathrm{AG}$ & 17 & $5039 \pm 642$ & & \\
\hline
\end{tabular}

and patient levels at $\mathrm{R}_{0}$. Paired Student $t$-tests were used for comparisons between patients before $\left(\mathrm{R}_{0}\right)$ and after $\left(\mathrm{R}_{1}\right)$ adjuvant radiotherapy.

The influence of SNPs on the levels of plasma biomarkers within the group of controls and patients at $\mathrm{R}_{0}$ or $\mathrm{R}_{1}$, were analysed. The influence of pathological conditions and SNPs on plasma biomarkers at $\mathrm{R}_{0}$ were analysed by comparisons between the controls and the patient with the SNP genotype using Student $t$-tests The influence of adjuvant RT and SNPs on plasma biomarkers were analysed by comparisons between patient levels at $\mathrm{R}_{0}$ and $\mathrm{R}_{1}$ using paired Student $t$-tests.

All statistical analyses were two-sided and the threshold for significance was set at $p \leq 0.05$.

\section{Results}

Characteristics of the patients and controls. A total of 86 female patients with breast cancer with a median age of 67 (range $=41-86$ ) years were prospectively included after recovery from surgery (Table I). The patients were heterogeneous regarding TNM stage and hormone-receptor expression in the tumour. The control cohort comprised 82 female healthy blood donors with a median age of 56 (range $=41-70$ ) years.

The median age of the patients was higher than that of the controls but this did not reach statistical significance (data not shown).

Plasma CRP, cytokine and chemokine levels in controls and patients before and after adjuvant RT. After recovery from the removal of their breast cancer mass, the patients had significantly higher plasma levels of CRP $(p=0.001)$ and CCL4 $(p=0.004)$ but a lower level of IL2 ( $p=0.003)$ than the controls (Table II). Despite similar levels of CCL5 in the controls and the patient at $\mathrm{R}_{0}$, adjuvant $\mathrm{RT}$ significantly reduced the plasma CCL5 level in patients $\left(\mathrm{R}_{0} v s . \mathrm{R}_{1}: p=0.01\right)$.

The influence of SNPs and adjuvant RT on plasma CRP, IL2, CCL4 and CCL5 levels in the controls and the patients 
Table IV. Influence of single nucleotide polymorphisms (SNP) on plasma levels (Mean \pm SD) of C-reactive protein (CRP), interleukin 2 (IL2), chemokine (C-C motif) ligand 4 (CCL4) and CCL5 among patients with breast cancer before (RO) and after (RI) adjuvant radiotherapy.

\begin{tabular}{|c|c|c|c|c|c|c|c|c|}
\hline \multirow[b]{2}{*}{ Parameter } & \multirow[b]{2}{*}{ SNP } & \multirow[b]{2}{*}{ Genotype } & \multirow[b]{2}{*}{$\mathrm{n}$} & \multicolumn{2}{|c|}{ Plasma level } & & \multicolumn{2}{|c|}{$p$-Value } \\
\hline & & & & $\mathrm{R}_{0}$ & $\mathrm{R}_{1}$ & & $\mathrm{R}_{0}$ & $\mathrm{R}_{1}$ \\
\hline \multirow[t]{2}{*}{$\mathrm{CRP}(\mathrm{mg} / \mathrm{l})$} & \multirow{2}{*}{ CRP rs1800947 } & $\mathrm{CC}$ & 71 & $4.6 \pm 0.6$ & $3.9 \pm 0.5$ & \multirow[t]{2}{*}{$\mathrm{CC} v s . \mathrm{CG}$} & \multirow[t]{2}{*}{0.05} & \multirow[t]{2}{*}{0.05} \\
\hline & & CG & 14 & $2.8 \pm 0.7$ & $2.1 \pm 0.4$ & & & \\
\hline \multirow[t]{2}{*}{ IL2 (pg/ml) } & \multirow{2}{*}{ IL2 rs6822844 } & $\mathrm{AC}$ & 27 & $9.9 \pm 1.8$ & $10.3 \pm 2$ & \multirow{2}{*}{$\mathrm{AC} v s . \mathrm{CC}$} & \multirow[t]{2}{*}{0.01} & \multirow[t]{2}{*}{0.09} \\
\hline & & $\mathrm{CC}$ & 59 & $20.9 \pm 3.5$ & $16.6 \pm 2.5$ & & & \\
\hline \multirow[t]{2}{*}{ CCL4 (pg/ml) } & \multirow[t]{2}{*}{ CCL4 rs1719153 } & AT & 30 & $57.3 \pm 3.6$ & $53.8 \pm 3.1$ & \multirow[t]{2}{*}{$\mathrm{AT} v s . \mathrm{TT}$} & \multirow[t]{2}{*}{0.80} & \multirow[t]{2}{*}{0.26} \\
\hline & & $\mathrm{TT}$ & 56 & $54.9 \pm 3.8$ & $47.8 \pm 3.5$ & & & \\
\hline \multirow[t]{3}{*}{ CCL5 (pg/ml) } & \multirow[t]{3}{*}{ CCL5 rs2107538 } & AA & 11 & $5811 \pm 469$ & $4891 \pm 701$ & AA $v s$. AG & 0.80 & 0.26 \\
\hline & & AG & 31 & $5984 \pm 349$ & $5872 \pm 424$ & AG $v s . \mathrm{GG}$ & 0.70 & 0.007 \\
\hline & & GG & 44 & $5261 \pm 328$ & $4183 \pm 300$ & AA $v s$. GG & 0.80 & 0.31 \\
\hline \multirow[t]{2}{*}{ CCL5 (pg/ml) } & \multirow[t]{2}{*}{ CCL5 rs2280789 } & AA & 69 & $5553 \pm 257$ & $4633 \pm 280$ & \multirow[t]{2}{*}{ AA vs. AG } & \multirow[t]{2}{*}{0.80} & \multirow[t]{2}{*}{0.09} \\
\hline & & AG & 17 & $5718 \pm 376$ & $5868 \pm 413$ & & & \\
\hline
\end{tabular}

before and after adjuvant $R T$. No statistically significant influence of the studied SNPs on the corresponding CRP, IL2, CCL4 and CCL5 levels were found in the controls (Table III). SNP variations in CRP rs1800947 and IL2 rs6822844 were significantly associated with levels of CRP ( $p=0.05)$ and IL2 $(p=0.01)$ of patients at $\mathrm{R}_{0}$. An impact of adjuvant RT and SNP sequence on the levels of CRP $(p=0.05)$ and CCL5 $(p=0.007)$ were detected in the patients at R1 (Table IV).

In those with the same SNP genotype (Table V), higher levels of CRP in the patients at $\mathrm{R}_{0}$ when compared to the controls were associated with $C R P$ rs 1800947 CC $(p=0.003)$. Lower levels of plasma IL2 in these patients were associated with IL2 rs6822844AC (Controls vs. patients at R0: $p=0.007)$. Combination effects of adjuvant RT and SNP on levels of plasma CCL5 were detected when comparing levels in patients at $\mathrm{R}_{0}$ with those at $\mathrm{R}_{1}$ based on CCL5 rs 2107538 GG $(p=0.04)$ and CCL5 rs2280789 AA $(p=0.05)$.

\section{Discussion}

Despite recovering from surgery, significantly elevated levels of CRP and CCL4, as well as down-regulation of immune modulator cytokine IL2 were detected in patients with breast cancer. It has been reported that CCL2 and CCL5 are highly expressed in breast cancer cells or cells found in the tumour microenvironment (17). Similar levels of plasma CCL2 and CCL5 in our controls and patients before adjuvant RT suggested that the majority of tumour cells were successfully removed by surgery. SNPs in CRP and IL2 gene were associated with plasma levels of CRP and IL2 in patients but not in the controls. Since all visible tumour mass were removed, SNPs might influence systemic inflammation and immunosuppressive condition among patients with breast cancer $(24,25)$.
Table V. Significance of differences in plasma levels of C-reactive protein (CRP), interleukin 2 (IL2), chemokine (C-C motif) ligand 4 $(C C L 4)$ and $C C L 5$ according to genotype when comparing controls and patients before $\left(R_{0}\right)$ and after $\left(R_{1}\right)$ adjuvant radiotherapy.

\begin{tabular}{lccc}
\hline & & \multicolumn{2}{c}{$p$-Value } \\
\cline { 3 - 4 } Gene & Genotype & $\begin{array}{c}\text { Controls } v s . \\
\text { patients at } \mathrm{R}_{0}^{*}\end{array}$ & $\begin{array}{c}\text { Patients: } \mathrm{R}_{0} \\
\text { vs. } \mathrm{R}_{1} * *\end{array}$ \\
\hline CRP rs 1800947 & CC & 0.003 & 0.09 \\
& CG & 0.9 & 0.9 \\
IL2 rs 6822844 & AC & 0.007 & 0.9 \\
& CC & 0.9 & 0.4 \\
CCL4 rs 1719153 & AT & 0.09 & 0.24 \\
CCL5 rs 2107538 & TT & 0.9 & 0.4 \\
& AA & 0.9 & 0.4 \\
CCL5 rs2280789 & AG & 0.9 & 0.9 \\
& GG & 0.8 & 0.04 \\
& AA & 0.9 & 0.05 \\
& AG & 0.9 & 0.4 \\
\hline
\end{tabular}

*Student's $t$-test. **Paired Student's $t$-test.

The majority of cells receiving adjuvant RT in our investigation were expected to be normal cells. RT-mediated cell death and its bystander effects can enhance host immune responses that contribute to the clinical outcome of patients $(5,15)$. An effect of adjuvant RT in our study was only documented for CRP and CCL5. The down-regulation of systemic inflammatory biomarkers CRP and CCL5 by adjuvant RT suggests a benefit from this treatment, especially in patients with $C R P$ rs 1800947 CC genotype and CCL5 rs2107538GG or CCL5 rs2280789 AA genotype (26).

Genetic variations based on SNP sequences had no influence on the plasma levels of these immune response biomarkers under healthy conditions. The lack of association 
between the levels of CCL4 and CCL4 rs1719153 might be due to the limited number of patients. Alternatively, the selected SNPs might only marginally influence CCL4 production in the systemic circulation.

The plasma levels of IL2, CRP and CCL5 have been suggested to be associated with the clinical outcome of patients with cancer $(12,13,19,27)$. Blood-based analyses of SNPs and plasma CRP, IL2 and CCL5 are low cost, rapid and can be undertaken using routine laboratory facilities while requiring only a peripheral blood sample. The possibility of using these blood-based biomarkers as indicators of immune status for selection of individual patient treatment warrants further investigation (28).

\section{Acknowledgements}

The Authors would like to thank the patients and healthy blood donors who participated in this study, Tomas Axelsson for SNPs analysis and the staff of Ryhov Hospital, Jönköping for practical support.

This investigation was partially supported by the Jönköping Clinical Cancer Research Foundation (Grant 110426-1), Futurum (Grant 144631), FORSS (Grant 567001), the Thai Office of Science and Technology in Brussels as well as the Ministry of Science and Technology. The funders had no role in study design, data collection and preparation of this manuscript or the decision to publish this investigation.

\section{Conflicts of Interest}

The Authors declare that they have no conflicts of interest to disclose in regard to this study.

\section{Authors' Contributions}

NL, LER, SL and FL designed the study and analysed the results. TL and $\mathrm{B} \AA \mathrm{A}$ carried out the blood-based biomarkers experiments and data. DO, MS and MN responsible for included the patients, adjuvant RT and statistical analysis. All authors wrote, read and approved this manuscript.

\section{References}

1 Laytragoon-Lewin N, Porwit-MacDonald A, Mellstedt $\mathrm{H}$ and Lewin F: Alteration of cellular mediated cytotoxicity, T-cell receptor zeta (TCR zeta) and apoptosis related gene expression in nasopharyngeal carcinoma (NPC) patients: Possible clinical relevance. Anticancer Res 20(2B): 1093-1100, 2000. PMID: 10810402

2 Wilson L, Lin T, Wang L, Patel T, Tran D, Kim S, Dacey K, Yuen C, Kroon L, Brodowy B and Rodondi K: Evaluation of the ASCO value framework for anticancer drugs at an academic medical center. J Manag Care Spec Pharm 23(2): 163-169, 2017. PMID: 28125363. DOI: 10.18553/jmcp.2017.23.2.163

3 Chen Q, Ayer T, Nastoupil LJ, Rose AC and Flowers CR: Comparing the cost-effectiveness of rituximab maintenance and radioimmunotherapy consolidation versus observation following first-line therapy in patients with follicular lymphoma. Value Health 18(2): 189-197, 2015. PMID: 25773554. DOI: 10.1016/ j.jval.2014.12.017
4 Abbasi J: Amid FDA approval filings, another CAR-T therapy patient death. JAMA 317(22): 2271, 2017. PMID: 28609515. DOI: $10.1001 /$ jama.2017.7153

5 Szatmari T, Persa E, Kis E, Benedek A, Hargitai R, Safrany G and Lumniczky K: Extracellular vesicles mediate low dose ionizing radiation-induced immune and inflammatory responses in the blood. Int J Radiat Biol: 1-11, 2018. PMID: 29533121. DOI: $10.1080 / 09553002.2018 .1450533$

6 Okunieff P, Chen Y, Maguire DJ and Huser AK: Molecular markers of radiation-related normal tissue toxicity. Cancer Metastasis Rev 27(3): 363-374, 2008. PMID: 18506399. DOI: 10.1007/s10555-008-9138-7

7 Rodemann HP and Blaese MA: Responses of normal cells to ionizing radiation. Semin Radiat Oncol 17(2): 81-88, 2007. PMID: 17395038. DOI: 10.1016/j.semradonc.2006.11.005

8 Liu H, Li B, Jia X, Ma Y, Gu Y, Zhang P, Wei Q, Cai J, Cui J, Gao $\mathrm{F}$ and Yang Y: Radiation-induced decrease of CD8+ dendritic cells contributes to Th1/Th2 shift. Int Immunopharmacol 46: 178185, 2017. PMID: 28314222. DOI: 10.1016/j.intimp.2017.03.013

9 Alsbeih G, Al-Harbi N, Al-Hadyan K, El-Sebaie M and Al-Rajhi $\mathrm{N}$ : Association between normal tissue complications after radiotherapy and polymorphic variations in TGFB1 and XRCC1 genes. Radiat Res 173(4): 505-511, 2010. PMID: 20334523. DOI: $10.1667 / \mathrm{RR} 1769.1$

10 van Leeuwen MA and van Rijswijk MH: Acute-phase proteins in the monitoring of inflammatory disorders. Baillieres Clin Rheumatol 8(3): 531-552, 1994. PMID: 7525084.

11 Roxburgh CS and McMillan DC: Role of systemic inflammatory response in predicting survival in patients with primary operable cancer. Future Oncol 6(1): 149-163, 2010. PMID: 20021215. DOI: $10.2217 /$ fon.09.136.

12 Andersson BA, Lewin F, Lundgren J, Nilsson M, Rutqvist LE, Lofgren S and Laytragoon-Lewin N: Plasma tumor necrosis factor-alpha and $\mathrm{C}$-reactive protein as biomarker for survival in head and neck squamous cell carcinoma. J Cancer Res Clin Oncol 140(3): 515-519, 2014. PMID: 24481866. DOI: $10.1007 / \mathrm{s} 00432-014-1592-8$

13 Fyfe G, Fisher RI, Rosenberg SA, Sznol M, Parkinson DR and Louie AC: Results of treatment of 255 patients with metastatic renal cell carcinoma who received high-dose recombinant interleukin-2 therapy. J Clin Oncol 13(3): 688-696, 1995. PMID: 7884429. DOI: 10.1200/JCO.1995.13.3.688

14 Rollins BJ: Chemokines. Blood 90(3): 909-928, 1997. PMID: 9242519.

15 Wang X, Yang X, Tsai Y, Yang L, Chuang KH, Keng PC, Lee SO and Chen Y: Il-6 mediates macrophage infiltration after irradiation via up-regulation of CCL2/CCL5 in non-small cell lung cancer. Radiat Res 187(1): 50-59, 2017. PMID: 28054838. DOI: $10.1667 / \mathrm{RR} 14503.1$

16 Lord BI, Dexter TM, Clements JM, Hunter MA and Gearing AJ: Macrophage-inflammatory protein protects multipotent hematopoietic cells from the cytotoxic effects of hydroxyurea in vivo. Blood 79(10): 2605-2609, 1992. PMID: 1586712.

17 Soria G and Ben-Baruch A: The inflammatory chemokines CCL2 and CCL5 in breast cancer. Cancer Lett 267(2): 271-285, 2008. PMID: 18439751. DOI: 10.1016/j.canlet.2008.03.018

18 Cocchi F, DeVico AL, Garzino-Demo A, Arya SK, Gallo RC and Lusso P: Identification of rantes, MIP-1 alpha, and MIP-1 beta as the major HIV-suppressive factors produced by cd8 $+\mathrm{t}$ cells. Science 270(5243): 1811-1815, 1995. PMID: 8525373. 
19 Halama N, Zoernig I, Berthel A, Kahlert C, Klupp F, SuarezCarmona M, Suetterlin T, Brand K, Krauss J, Lasitschka F, Lerchl T, Luckner-Minden C, Ulrich A, Koch M, Weitz J, Schneider M, Buechler MW, Zitvogel L, Herrmann T, Benner A, Kunz C, Luecke S, Springfeld C, Grabe N, Falk CS and Jaeger D: Tumoral immune cell exploitation in colorectal cancer metastases can be targeted effectively by anti-CCR5 therapy in cancer patients. Cancer Cell 29(4): 587-601, 2016. PMID: 27070705. DOI: $10.1016 /$ j.ccell.2016.03.005

20 Weitzenfeld $\mathrm{P}$ and Ben-Baruch A: The chemokine system, and its CCR5 and CXCR4 receptors, as potential targets for personalized therapy in cancer. Cancer Lett 352(1): 36-53, 2014. PMID: 24141062. DOI: 10.1016/j.canlet.2013.10.006

21 Laytragoon-Lewin N, Cederblad L, Andersson BA, Olin M, Nilsson M, Rutqvist LE, Lundgren J, Engstrom M, Tytor W, Lofgren S and Lewin F: Single-nucleotide polymorphisms and cancer risk, tumor recurrence, or survival of head and neck cancer patients. Oncology 92(3): 161-169, 2017. PMID: 27997918. DOI: $10.1159 / 000452278$

22 Kiang JG, Smith JT, Anderson MN, Elliott TB, Gupta P, Balakathiresan NS, Maheshwari RK and Knollmann-Ritschel B: Hemorrhage enhances cytokine, complement component 3, and caspase-3, and regulates microRNAs associated with intestinal damage after whole-body gamma-irradiation in combined injury. PLoS One 12(9): e0184393, 2017. PMID: 28934227. DOI: 10.1371/journal.pone. 0184393

23 Steemers FJ, Chang W, Lee G, Barker DL, Shen R and Gunderson KL: Whole-genome genotyping with the single-base extension assay. Nat Methods 3(1): 31-33, 2006. PMID: 16369550. DOI: $10.1038 /$ nmeth842
24 Gao Y and Huang D: The value of the systematic inflammationbased Glasgow prognostic score in patients with gastric cancer: A literature review. J Cancer Res Ther 10(4): 799-804, 2014. PMID: 25579511. DOI: 10.4103/0973-1482.146054

25 Coussens LM and Werb Z: Inflammation and cancer. Nature 420(6917): 860-867, 2002. PMID: 12490959. DOI: 10.1038/ nature 01322

26 Kurt RA, Baher A, Wisner KP, Tackitt S and Urba WJ: Chemokine receptor desensitization in tumor-bearing mice. Cell Immunol 207(2): 81-88, 2001. PMID: 11243697. DOI: 10.1006/ cimm.2000.1754

27 Velasco-Velazquez M, Xolalpa W and Pestell RG: The potential to target CCL5/CCR5 in breast cancer. Expert Opin Ther Targets 18(11): 1265-1275, 2014. PMID: 25256399. DOI: 10.1517/ 14728222.2014.949238

28 Vatner RE, Cooper BT, Vanpouille-Box C, Demaria S and Formenti SC: Combinations of immunotherapy and radiation in cancer therapy. Front Oncol 4: 325, 2014. PMID: 25506582. DOI: $10.3389 /$ fonc .2014 .00325
Received January 21, 2019

Revised February 11, 2019

Accepted February 14, 2019 